\title{
Optimization of Reaction Conditions for Synthesis of Carboxymethyl Cellulose from Oil Palm Fronds
}

\author{
Penpun Tasaso
}

\begin{abstract}
Oil palm fronds is an agricultural waste derives from the harvesting of oil palm fruit bunches, rich in fiber and cellulosic compound. This work reported the utilization of oil palm fronds for synthesis carboxymethyl cellulose (CMC). The optimization of reaction conditions was studied by using response surface methodology (RSM). The design experiment is central composite design consists of 2 factors $(\% \mathrm{NaOH}$ in mercerization process and weight of monochloroacetic acid in etherification process) with 5 levels. It was found that at optimum condition: $52 \% \mathrm{NaOH}$ and $10.7 \mathrm{~g}$ of MCA, at reaction temperature of $50{ }^{\circ} \mathrm{C}$ with $3 \mathrm{~h}$ of reaction time, given the highest yield of $170.1 \%$ CMC. Synthesized oil palm fronds CMC obtained at this condition was characterized, which has DS of 1.1, purity $97.3 \%$, viscosity of $1 \%$ w/v CMC solution was $685 \mathrm{cP}$. This synthesized oil palm fronds CMC could be categorized as technical grade CMC.
\end{abstract}

Index Terms-Carboxymethyl cellulose, oil palm fronds, optimization, response surface methodology.

\section{INTRODUCTION}

Oil palm fronds are a by-product of the cultivation of oil palm trees. The rapid development of the palm oil industry since the 1990s, notably in South-East Asia (Thailand, Malaysia and Indonesia), has caused an increasing output of fibrous wastes derived from the harvesting of oil palm fruit bunches. It can be estimated that 164 million ton Dry Mass of oil palm fronds are produced every year in the world. Oil palm fronds are a low-protein, contain high amounts of fiber in neutral detergent fiber, NDF and acid detergent fiber, ADF The content are in the $63-80 \%$ range and $45-57 \%$ range respectively. Therefore oil palm fronds could be a good source for production of cellulose derivatives.

Cellulose is a simple linear polymer consisting of anhydroglucopyranose unit (AGU) linked together with $\beta$ - $(1,4)$-glycosidic bonds formed between carbon 1 and carbon 4 of adjacent glucose. Each of the AGU units consists of three hydroxyl groups at carbon 2,3 and 6 positions. Cellulose is aligned parallel to each other in fibrils, which are surrounded by a matrix of lignin and hemicellulose In addition, cellulose has properties such as low density, good mechanical properties as well as bio degradability [1], [2].

Carboxymethyl cellulose, CMC is a linear, long chain, water soluble, anionic polysaccharide derived from cellulose. The preparation of CMC involves two reaction steps, which are alkalization and etherification process. In the alkalization process, the cellulose is treated with $\mathrm{NaOH}$, often in the presence of inert solvent (ethanol or isopropanol),

Manuscript received May 15, 2014; revised July 9, 2014

Penpun Tasaso is with the Department of Chemical Engineering, Mahidol University Nakornpathom 73170 Thailand (e-mail: penpun.tas@ mahidol.ac.th). which acts both as a swelling agent and as a dilutant which facilitates good penetration to the crystalline structure of cellulose. It solvates the hydroxyl groups and thus makes them available for etherification reaction. The alkalization process is generally performed at room temperature. In etherification step the alkali cellulose is reacted with monochloroacetate acid (NaMCA), or as free acid, monochloroacetic acid (MCA) to form carboxymethyl cellulose ethers. At the same time $\mathrm{NaOH}$ reacts with MCA to form two by-products, which are sodium glycolate and sodium chloride. The reaction in alkalization, etherification and side reaction process are as shown in equation (1), (2) and (3) respectively

$$
\begin{aligned}
& {\left[\mathrm{C}_{6} \mathrm{H}_{7} \mathrm{O}_{2}(\mathrm{OH})_{3}\right]_{\mathrm{n}}+} \\
& \mathrm{nNaOH} \rightarrow\left[\mathrm{C}_{6} \mathrm{H}_{7} \mathrm{O}_{2}(\mathrm{OH})_{2} \mathrm{ONa}\right]_{\mathrm{n}}+\mathrm{nH}_{2} \mathrm{O} \\
& {\left[\mathrm{C}_{6} \mathrm{H}_{7} \mathrm{O}_{2}(\mathrm{OH})_{2} \mathrm{ONa}\right]_{n}+\mathrm{nClCH}_{2} \mathrm{COONa}} \\
& \rightarrow\left[\mathrm{C}_{6} \mathrm{H}_{7} \mathrm{O}_{2}(\mathrm{OH})_{2} \mathrm{OCH}_{2} \mathrm{COONa}\right]_{\mathrm{n}}+\mathrm{n} \mathrm{NaCl}
\end{aligned}
$$

$$
\mathrm{NaOH}+\mathrm{ClCH}_{2} \mathrm{COONa} \rightarrow \mathrm{HOCH}_{2} \mathrm{COONa}+\mathrm{NaCl}
$$

CMC is currently many applications in industry such as enhanced the physical property of paper, as drilling mud in oil industry, as a dye thickening in textile industry. In form of purified CMC, it was used in food, pharmaceutical, detergent and cosmetic industries [3], [4]. Therefore the purpose of this study was to synthesis CMC from oil palm fronds, which is the abundant of waste in the south region of Thailand, and the optimization of reaction conditions was also investigated.

\section{EXPERIMENTAL PROCEDURE}

The materials used in this research are oil palm fronds obtained from Surath thani province, Thailand. All chemicals used were AR grade.

\section{A. Extraction of Cellulose}

Oil palm fronds was rinsed with water and sun-dried for 4 days. It was cut in to small pieces then dried at $70{ }^{\circ} \mathrm{C}$ in oven dryer. The dried product was ground into powder with disc mill to pass through a 42 mesh sieve. The $50 \mathrm{~g}$ of oil palm fronds powder was cooked in 1 litre of $10 \% \mathrm{NaOH}$ at $130{ }^{\circ} \mathrm{C}$ under pressure $190 \mathrm{kPa}$ for 60 minutes. The obtained black slurry was filtered and washed solid residue with distilled water. The residue was dried at $70^{\circ} \mathrm{C}$ to constant weight for $24 \mathrm{~h}$, and oil palm fronds cellulose was obtained. The cellulose was bleached with $30 \% \mathrm{H}_{2} \mathrm{O}_{2}$ at $70{ }^{\circ} \mathrm{C}$ for $3 \mathrm{~h}$. The bleached cellulose was washed again using distilled water and filtered then dried the bleached cellulose at $70{ }^{\circ} \mathrm{C}$. The bleached cellulose was ground with blender into powder then 
sieved, size less than 350 micron was used in experiments.

\section{B. Synthesis of Carboxymethyl Cellulose}

$15 \mathrm{~g}$ of bleached oil palm fronds cellulose powder was alkalized at $30^{\circ} \mathrm{C}$ for $60 \mathrm{~min}$ in water bath shaker with $50 \mathrm{ml}$ $\mathrm{NaOH}$ of various concentrations $(37.9,40,45,50$ and $52.1 \%$ ) in $450 \mathrm{ml}$ isopropanol as a solvent. After the alkalization process is over, the etherification process was followed by the addition of various amount of monochloroacetic acid $\left(10.7,12,15,18\right.$ and $19.2 \mathrm{~g}$.) at $50^{\circ} \mathrm{C}$ for $3 \mathrm{~h}$. The slurry was filtrated and solid was suspended in methanol and neutralized with $90 \%$ acetic acid. The solid obtained as CMC was washed by $80 \%$ ethanol for four times to remove undesirable byproducts. The CMC products was dried at $60{ }^{\circ} \mathrm{C}$ for $6 \mathrm{~h}$. The yield, express as a percentage, was calculated based on the amount of cellulose used as in equation (4). Verification process was carried out based on simulation process using response surface methodology output.

$$
\text { Yield of CMC }(\%)=\frac{\text { Weight of CMC }(g)}{\text { Weight of cellulose }(g)} \times 100
$$

\section{Characterization of Carboxymethyl Cellulose}

The moisture content, degree of substitution (DS), and purity of CMC were determined by the ASTM D1439-94 standard method (ASTM, 1994) [5].

\section{Infrared Spectroscopy}

All measurement were carried out using the $\mathrm{KBr}$ method. About $0.2 \mathrm{mg}$ of sample and $2 \mathrm{mg}$ of $\mathrm{KBr}$ were mixed and ground finely and the mixture was compressed to a form of transparent disk. The infrared spectra were recorded with a Thermo Scientific Spectrophotometer (Nicolet 6700) between $400-4000 \mathrm{~cm}^{-1}$. The substitution reaction was confirmed by the presence of the $\mathrm{COO}^{-},-\mathrm{CH}_{2}$ and - O- group in the IR spectrum.

\section{E. Surface Morphology Analysis}

The scanning electron microscope (SEM) was used to analyzed the morphology of cellulose and CMC. The morphology of sample was performed using scanning electron microscope, SEM-5410LV with 500X.

\section{F. Statistical Analysis}

Response surface methodology (RSM) was used to analyze the optimum condition for CMC synthesis. The design experiment is central composite design (CCD) consists of 2 factors ( $\mathrm{NaOH}, \mathrm{MCA})$ in which 5 levels of each with alpha equal to \pm 1.414 (total of 11 experiments). Data was processed with data analysis function in excel program. The factors and levels of process parameter in coded variable and actual value are as shown in Table I.

\section{RESULTS AND DISCUSSION}

\section{A. Percentage Yield of Cellulose and Carboxymethyl Cellulose (CMC)}

The yield of cellulose extracted from the oil palm fronds powder and also the yield of CMC synthesized was measured based on the dry weight basis. After alkaline treatment and bleaching the yield of cellulose extracted from oil palm fronds was $30.6 \%$. Table II shows the percentage yield of CMC synthesized at different reaction conditions. The percentage yield of CMC increased with increasing \% $\mathrm{NaOH}$ concentration due to the reaction of cellulose with monochloroacetic acid (MCA) in an alkaline condition causes the substitution of the hydroxyl group of cellulose molecules with carboxymethyl group and attributed to a higher mass. In Fig. 1 the correlation between percentage yield and degree of substitution (DS) of CMC was illustrated. The results showed that higher the DS, higher the yield of CMC.

The DS values obtained at different reaction conditions were analyzed by using second-order polynomial regression analysis. The model for DS prediction was calculated and expressed in coded variable as in equation (5) where $X_{1}$ is coded variable of $\% \mathrm{NaOH}$ and $X_{2}$ is coded variable of weight of MCA respectively.

TABLE I: FACTORS AND LEVESL OF PROCESS PARAMETER FOR SYNTHESIZED CMC IN CODED VARIABLE AND ACTUAL VALUE

\begin{tabular}{|c|c|c|c|c|c|}
\hline \multirow{2}{*}{ Factors } & \multicolumn{5}{|c|}{ Level } \\
\cline { 2 - 6 } & -1.414 & -1 & 0 & 1 & 1.414 \\
\hline$\% \mathrm{NaOH}$ & 37.9 & 40 & 45 & 50 & 52.1 \\
\hline $\begin{array}{c}\text { Wt. of } \\
\text { MCA (g) }\end{array}$ & 10.7 & 12 & 15 & 18 & 19.2 \\
\hline
\end{tabular}

TABLE II: The PERCENTAGE YIELD AND DS OF SYNTHESIZED OIL PALM

\begin{tabular}{|c|c|c|c|c|}
\hline Frond CMC AT DIFFERENT REACTION CONDITION \\
\hline Experiment & $\% \mathrm{NaOH}$ & $\begin{array}{c}\text { Weight of } \\
\text { MCA }(\mathrm{g})\end{array}$ & $\%$ Yield & DS \\
\hline 1 & -1 & -1 & 160.0 & 0.76 \\
\hline 2 & 1 & -1 & 163.4 & 0.92 \\
\hline 3 & -1 & 1 & 141.8 & 0.74 \\
\hline 4 & 1 & 1 & 170.2 & 0.95 \\
\hline 5 & -1.414 & 0 & 140.0 & 0.57 \\
\hline 6 & 1.414 & 0 & 159.8 & 0.69 \\
\hline 7 & 0 & -1.414 & 150.4 & 0.71 \\
\hline 8 & 0 & 1.414 & 156.0 & 0.69 \\
\hline 9 & 0 & 0 & 162.6 & 0.86 \\
\hline 10 & 0 & 0 & 161.6 & 0.82 \\
\hline 11 & 0 & 0 & 160.4 & 0.83 \\
\hline
\end{tabular}

$$
\begin{aligned}
D S= & 0.8417+0.08 X_{1}-0.025 X_{2}-0.037 X_{1} X_{2}- \\
& 0.0511 X_{1}^{2}-0.0144 X_{2}^{2}
\end{aligned}
$$

From equation (5), the response surface plots of DS and contour plots were obtained as shown in Fig. 2 and Fig. 3.

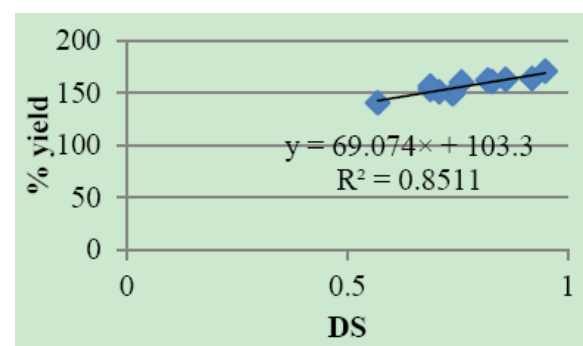

Fig. 1. Correlation between percentage yield of synthesized CMC and DS of CMC.

Data in Fig. 2 and Fig. 3 Show $\% \mathrm{NaOH}$ and weight of MCA in coded variable which converted to actual value as shown in Table I. From Fig. 2 it found that increased of DS was depended significantly by increased of $\% \mathrm{NaOH}$ than that of increased of MCA. It was suggested that synthesis of CMC from oil palm fronds cellulose affected by $\% \mathrm{NaOH}$ due to the crystalline region in cellulose was changed to 
amorphous and thus, atom at $\mathrm{C}_{2}, \mathrm{C}_{3}$ and $\mathrm{C}_{6}$ of anhydroglucopyranose unit (AGU) could be easily accessed by MCA. [5]-[7] The DS attained a maximum of 0.95 at $52.1 \% \mathrm{NaOH}$ and $10.7 \mathrm{~g}$ of $\mathrm{MCA}$, given the highest yield of $170.1 \%$. To verify the optimum condition achieved from RSM, the experiment was done at this condition, the synthesized oil palm fronds CMC obtained has DS of 1.1 which was $15 \%$ error from predicted RSM. To compare \% $\mathrm{NaOH}$ used to synthesize oil palm fronds CMC of this research with other work, it seem to be at high concentration, may be because of this experiment used monochloroacetic acid in the etherification process. The $\mathrm{pH}$ in this reaction system is important to remain the alkalinity. According to Klemm the reaction requires at least 0.8 mole of $\mathrm{NaOH}$ per molecule of AGU to remain the alkalinity if the etherifying agent used is NaMCA. However, if MCA is used instead, thus extra mole of $\mathrm{NaOH}$ per mole of AGU must be added to neutralize the acid. [7] The other factors that effect to DS are reaction temperature and reaction time which was not varied in this experiment because it was studied in my previous work.

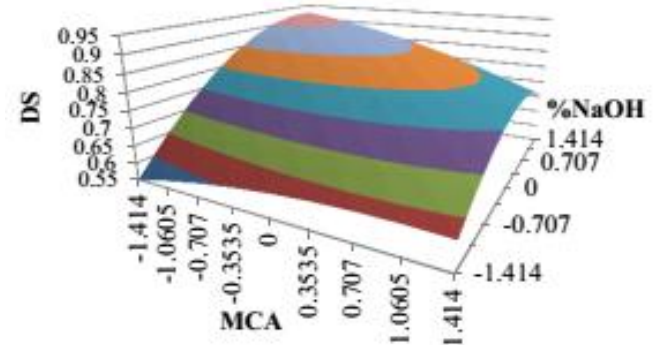

Fig. 2. Surface plot of DS versus $\% \mathrm{NaOH}$ and MCA.

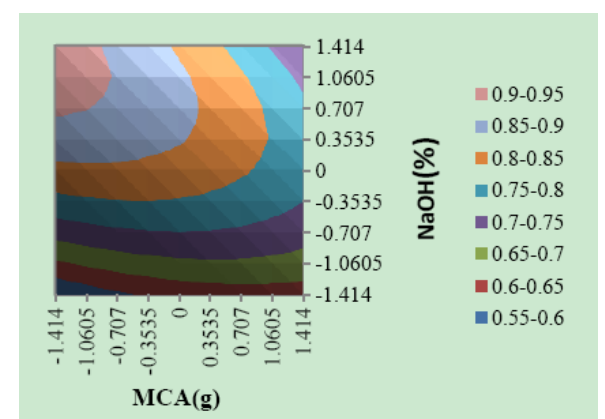

Fig. 3. Contour plots of DS at various $\% \mathrm{NaOH}$ and MCA.

From contour plots in Fig. 3, it was found that the predicted DS of synthesized oil palm fronds CMC was in the range of $0.55-0.95$. Therefore synthesized oil palm fronds CMC can be used in many application such as in paper or textile industry.

\section{B. The Infrared Spectroscopy}

The infrared spectra were studied to confirmed the substitution reaction in etherification step. The infrared spectra of native oil palm fronds cellulose was presented in Fig. 4 and FTIR spectra of synthesized oil palm fronds CMC was shown in Fig. 5. The broad absorption band at $3300 \mathrm{~cm}^{-1}$ is due to the streching frequency of the $-\mathrm{OH}$ group. The band at $2920 \mathrm{~cm}^{-1}$ due to $\mathrm{C}-\mathrm{H}$ streching vibartion. The band around 1420 and $1320 \mathrm{~cm}^{-1}$ are assigned to $-\mathrm{CH}_{2}$ scissoring and $-\mathrm{OH}$ bending vibration respectively. The presence of the new and strongest absorbance of synthesized oil palm fronds $\mathrm{CMC}$ were at 1587,1414 and $1322 \mathrm{~cm}^{-1}$. The wave number $1587 \mathrm{~cm}^{-1}$ is plot of $\mathrm{C}=\mathrm{O}$ group streching of acetyl or carboxymethyl. Salt of carboxyl group had wave number about $1600 \mathrm{~cm}^{-1}$ and $1400-1450 \mathrm{~cm}^{-1}$ according to Biswal and Sing. This result confirmed that CMC could be synthesized from oil palm fronds [8].

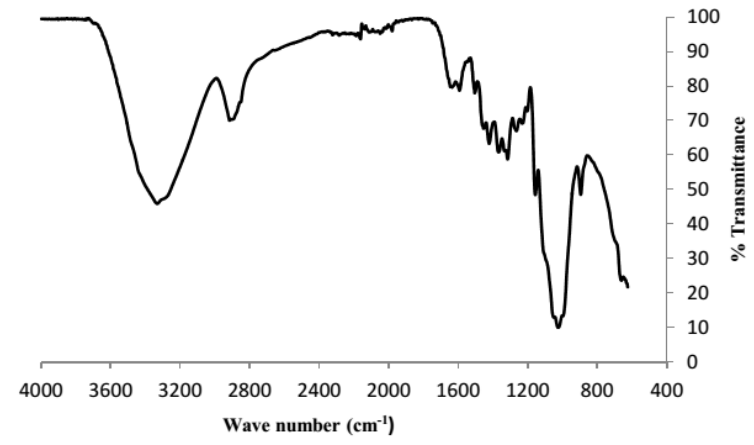

Fig. 4. FTIR spectra of native oil palm fronds cellulose.

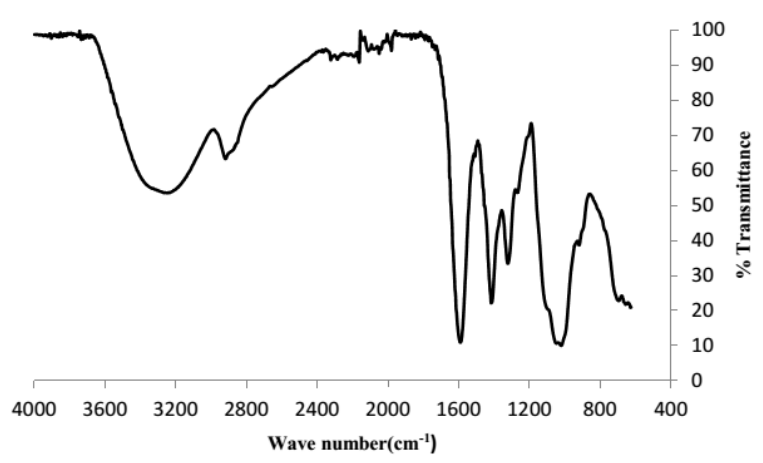

Fig. 5. FTIR spectra of synthesized oil palm fronds CMC.

\section{CMC Morphology}

The SEM at 500X was shown in Fig. 6, present the oil palm fronds cellulose (a), synthesized oil palm fronds CMC (b) and commercial CMC ( from Fluka Co., DS = 0.9) (c). The exterior surface of cellulose showed rough and their fiber were twisted and ruptured, may be caused of using strongly chemicals and high temperature in cellulose extraction process. For synthesized CMC the roughness were slightly decreased when compared with cellulose, this result caused of cellulose cryatallinity was changed to allow the etherifying agent to have access to the cellulose molecule [5]. Another technique was used to confirm that the synthesized product was CMC, by characterized the sample with Energy dispersive spectrometry (EDS) to detect the elements within the sample. The results of EDS was shown as in Fig. 7. The elements found in oil palm fronds cellulose and synthesized oil palm fronds CMC such as carbon, oxygen were almost similar except that $\mathrm{Na}$ which was found only in CMC. Therefore the sample CMC products were successfully synthesized from oil palm fronds cellulose with $\mathrm{NaOH}$ and MCA.

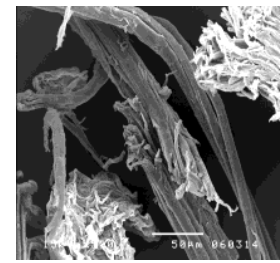

(a)

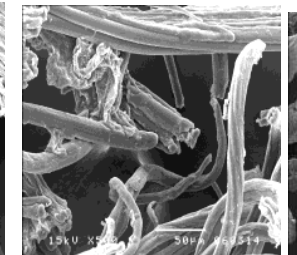

(b)

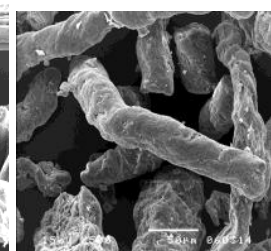

(c)
Fig. 6. SEM micrograph of oil palm fronds cellulose (a), synthesized oil palm fronds CMC at optimum condition (b) and commercial CMC ( from Fluka Co., DS = 0.9) (c). 


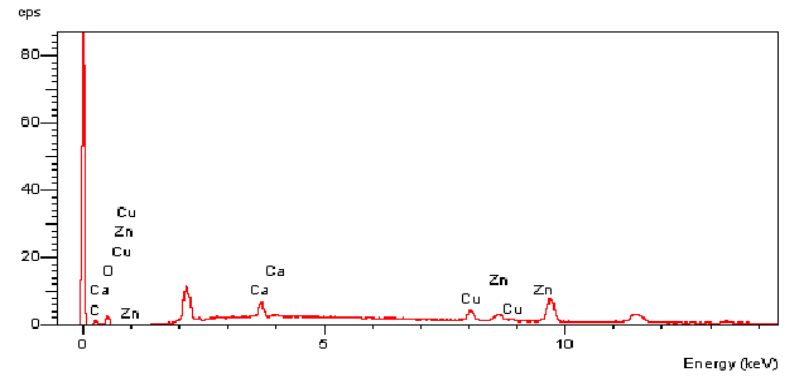

(a)

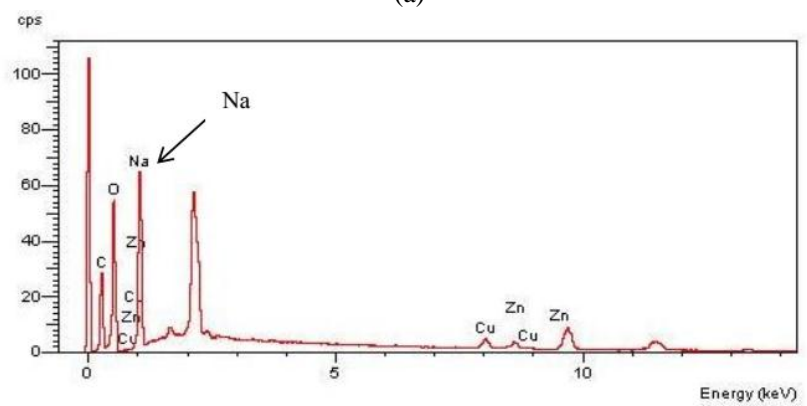

(b)

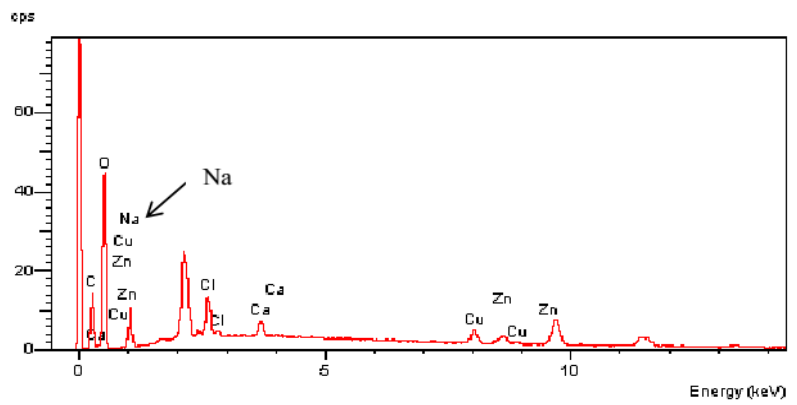

(c)

Fig. 7. Detected elements by using EDS in oil palm fronds cellulose (a), commercial CMC (b) and synthesized oil palm fronds CMC.

\section{Characterization of Carboxymethyl Cellulose}

The synthesized oil palm fronds CMC obtained at optimum condition of reaction was characterized and compared with commercial CMC at nearly DS value, the results were as shown in Table III. The purity of the CMC samples were measured after washing the products several times with $80 \%$ ethanol and absolute methanol, which remove the reaction by-products (Sodium chloride and sodium glycolate) The purity of synthesized CMC was $97.3 \%$ which lower than $99 \%$ of commercial CMC. The viscosity of $1 \%(\mathrm{w} / \mathrm{v})$ was $685 \mathrm{cP}$, categorized as low viscosity CMC.

TABLE III: CHARACTERISTICS OF SYNTHESIZED AND COMMERCIAL CMC

\begin{tabular}{|l|c|c|}
\hline Parameters & Synthesized CMC & Commercial CMC \\
\hline DS & 1.1 & 0.9 \\
\hline $\begin{array}{l}\text { Viscosity of 1\% (w/v) } \\
\text { solution,cP }\end{array}$ & 685 & 9,850 \\
\hline Purity (\%) & 97.3 & 99.1 \\
\hline Moisture (\%) & 5.4 & 5.5 \\
\hline
\end{tabular}

\section{CONCLUSION}

Cellulose can be extracted from oil palm fronds. Furthermore, the cellulosed could be modified to carboxymethyl cellulose having DS 1.1 at optimum condition of $52.1 \% \mathrm{NaOH}$ and $10.7 \mathrm{~g}$ of MCA, given the highest \% yield of 170.1 with $97.3 \%$ purity.

\section{ACKNOWLEDGMENT}

The author is gratefully acknowledge National Research Council of Thailand for financial support.Also special thanks to Department of Chemical Engineering, Mahidol University for providing research facilities to carry out the research.

\section{REFERENCES}

[1] A. Latif, T. Anwar, and S. Noor, "Two step synthesis and characterization of carboxymethylcellulose from rayon grade wood pulp and cotton linter," Jour. Chem. Soc. Pak, vol. 29, no. 2, pp. 143-150, 2007.

[2] V. Pushpamalar, S. J. Langford, M. Ahmad, and Y. Y. Lim, "Optimization of reaction conditions for preparing carboxymethylcellulose from sago waste," Carbohydrate Polymers, vol. 64 , pp. 312-318, 2006.

[3] H. D. Heydasadeh, G. D. Najafpour, and A. A. Nazari-Moghaddam, "Catalyst - free conversion of alkaline cellulose to fine carboxymethyl cellulose," World Applied Science Journal, vol. 6, no. 4, pp. 564-569, 2009.

[4] M. P. Adinugraha, D. W. Marseno, and Haryadi, "Synthesis and characterization of sodium carboxymethylcellulose from Cavendish banana pseudo stem ( Musa cavendishii LAMBERT)," Carbohydrate Polymers, vol. 62, pp. 164-169, 2005.

[5] P. Rachatanapun, S. Luangkamin, K. Tanprasert, and R. Suriyatem, "Carboxymethyl cellulose from durian rind," $L T W$ - Food Science and Technology, vol. 48, p p. 52-58, 2012.

[6] A. B. M. F. Alam and M. I. H. Mondal, "Utilization of cellulosic wastes in textile and garment industries I. Synthesis and grafting characterization of carboxymethylcellulose from knitted rag," J. APPL POLYM SCI, 2012.

[7] A. S. Saputra, L. Qadhayna, and A. B. Pitaloka, "Synthesis and characterization of carboxymethylcellulose (CMC) from Water Hyacinth using ethanol- isobutyl alcohol mixture as the solvent," International Journal of Chemical Engineering and Application, vol. 5, no. 1, pp. 36-40, Feb. 2014.

[8] G. S. Hutomo, D. W. Marseno, S. Anggrahini, and Supriyanto, "Synthesis and characterization of sodium carboxymethylcellulose from pod husk of Cacao( Theobroma cacao L.)," African Journal of Food Science, vol. 6, no. 6, pp. 180-185,Mar., 2012.

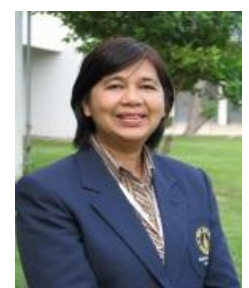

P. Tasaso obtained B.Sc. in chemical engineering, M.Eng. in chemical Eng. At present she is an assistant professor in the Department of Cmical Engineering, Mahidol University. Her area of interest is the extraction of valuable products from agricultural waste. She is a member of Thai Institute of Chemical Engineering and Applied Chemistry. 